severe exacerbation and time to first URI. Secondary outcomes included peak severity and area under the curve for exacerbation symptoms. A pre-specified sub-group analysis was conducted to determine whether effects of the intervention on co-primary outcomes were modified by baseline vitamin D status. This trial is registered with ClinicalTrials.gov (NCT00977873).

Results 122 participants were allocated to the intervention arm of the trial, and 118 to the control arm. Vitamin D supplementation did not influence time to first exacerbation (HR 0.86, 95\% CI $0.60-1.24, \mathrm{p}=0.42$ ) or time to first URI (HR 0.95, 95\% CI $0.69-1.31, \mathrm{p}=0.75)$ in the study population as a whole, but it did reduce peak severity $(\mathrm{p}=0.042)$ and area under the curve ( $\mathrm{p}=0.032$ ) for exacerbation symptoms. Pre-specified sub-group analysis revealed that vitamin $\mathrm{D}$ supplementation was protective against moderate/severe exacerbation among the 148 participants with baseline serum 25 -hydroxyvitamin D $(25[\mathrm{OH}] \mathrm{D})$ concentration $<50 \mathrm{nmol} / \mathrm{L}(\mathrm{aHR} 0.57,95 \%$ CI 0.35 to $0.92, \mathrm{p}=0.021$ ), but not among the 92 participants with baseline serum $25(\mathrm{OH})$ $\mathrm{D} \geq 50 \mathrm{nmol} / \mathrm{L}(\mathrm{aHR} 1.45,95 \% \mathrm{CI} 0.81$ to $2.62, \mathrm{p}=0.21 ; \mathrm{P}$ for interaction $=0.021$ ). Baseline vitamin $\mathrm{D}$ status did not modify the effect of vitamin D supplementation on risk of URI ( $P$ for interaction $=0.41$ ).

Conclusions Vitamin D supplementation protected against moderate/severe exacerbation, but not upper respiratory infection, in COPD patients with baseline $25(\mathrm{OH}) \mathrm{D}<50 \mathrm{nmol} / \mathrm{L}$. It also modestly reduced peak severity and area under the curve for exacerbation symptom scores, irrespective of baseline vitamin D status.

\section{S105 THE EFFECTS OF REAL-WORLD EXPOSURES TO DIESEL TRAFFIC EMISSIONS ON CARDIO-RESPIRATORY OUTCOMES IN COPD : 'OXFORD STREET 2'}

${ }^{1} \mathrm{R}$ Sinharay, ${ }^{2} \mathrm{~B}$ Barratt, ${ }^{3} \mathrm{~J}$ Gong, ${ }^{1} \mathrm{C}$ Goward, ${ }^{1} \mathrm{JP}$ Rocha, ${ }^{2} \mathrm{~F}$ Kelly, ${ }^{3} \mathrm{~J}$ Zhang, ${ }^{4} \mathrm{P}$ Cullinan, ${ }^{1} \mathrm{KF}$ Chung. 'Royal Brompton and Harefield NHS Foundation Trust, Imperial College, London, UK; ${ }^{2}$ Kings College Environmental Research Group, London, UK; ${ }^{3}$ Duke Global Health Initiative, Durham, United States; ${ }^{4}$ Royal Brompton and Harefield NHS Foundation Trust, London, UK

\subsection{6/thoraxjnl-2014-206260.111}

Introduction and objectives We studied the changes in lung function and cardiovascular responses in healthy volunteers and patients with COPD exposed to the high pollution levels in a busy London street.

Methods Using a cross-over design, 37 healthy volunteers and 37 COPD patients (walked along Oxford Street (diesel only traffic) and, on a separate occasion, in Hyde Park (low or little traffic), London for two hours. Cardio-respiratory measurements were performed at baseline, and during and after each exposure, alongside personal particulate and gaseous exposure measurements.

Findings Compared to Hyde Park, mean exposures on Oxford Street had higher levels of black carbon $\left(10.4 \mu \mathrm{m} / \mathrm{m}^{3}\right.$ vs. $1.2 \mu \mathrm{m} /$ $\left.\mathrm{m}^{3}, \mathrm{p}<0.001\right)$ and ultrafine particle counts $\left(25472 / \mathrm{cm}^{3}\right.$ vs $\left.5709 / \mathrm{cm}^{3}, \mathrm{p}<0.001\right)$.

In comparison with Hyde Park the healthy subjects had a mean fall in $\mathrm{FEV}_{1}$ from baseline of $6.05 \%(\mathrm{p}=0.01) 6 \mathrm{~h}$ and $\mathrm{a}$ fall of $4.17 \%(p=0.01) 24 \mathrm{~h}$ after arrival in Oxford St. There was no associated drop in FVC. Arterial stiffness measured by pulse wave velocity (PWV) increased $24 \mathrm{~h}$ after arriving on Oxford Street.

In volunteers with COPD, there was a mean fall in $\mathrm{FEV}_{1}$ of $4 \%(\mathrm{p}=0.01)$ with an associated drop in FVC of $3.4 \%(\mathrm{p}=$
Abstract S105 Table 1 Mean changes in, FVC, at IOS 5Hz andHz, FeNO and PWV after exposures began in Oxford Street (OS) and Hyde Park (HP)

\begin{tabular}{lllllllll} 
Healthy & \multicolumn{10}{c}{ COPD } \\
\hline OS & HP & $\Delta d$ & $p$ & OS & HP & $\Delta d$ & $p$ \\
\hline
\end{tabular}

\begin{tabular}{|c|c|c|c|c|c|c|c|c|}
\hline \multicolumn{9}{|c|}{ Spirometry (difference\%) } \\
\hline $\mathrm{FEV}_{1} 1 \mathrm{~h}$ & 0.78 & 3.46 & -2.68 & 0.09 & -2.30 & 1.70 & -4.00 & 0.01 * \\
\hline $\mathrm{FEV}_{1} 2 \mathrm{~h}$ & 0.49 & 2.38 & -1.89 & 0.17 & -1.43 & -0.38 & -1.05 & 0.39 \\
\hline $\mathrm{FEV}_{1} 6 \mathrm{~h}$ & 1.84 & 7.89 & -6.05 & 0.01 * & 1.68 & 2.08 & -0.41 & 0.79 \\
\hline $\mathrm{FEV}_{1} 24 \mathrm{~h}$ & 0.05 & 4.22 & -4.17 & 0.01 * & 1.85 & 0.92 & 0.93 & 0.65 \\
\hline FVC $1 \mathrm{~h}$ & 0.00 & 1.81 & -1.81 & 0.28 & -1.84 & 1.57 & -3.41 & 0.02 * \\
\hline FVC $2 \mathrm{~h}$ & -1.00 & 1.16 & -2.16 & 0.32 & -3.22 & -0.11 & -3.11 & 0.09 \\
\hline FVC $6 \mathrm{~h}$ & 0.22 & 3.57 & -3.35 & 0.17 & 1.38 & 1.60 & -0.22 & 0.90 \\
\hline FVC $24 \mathrm{~h}$ & -1.60 & -2.84 & 1.24 & 0.68 & 1.60 & 2.54 & -0.95 & 0.73 \\
\hline \multicolumn{9}{|c|}{ IOS $5 \mathrm{hz}$ (difference $\mathrm{kPa} / \mathrm{l} / \mathrm{s}$ ) } \\
\hline IOS $5 \mathrm{hz} 4 \mathrm{~h}$ & -0.01 & -0.01 & 0.00 & 0.78 & 0.03 & -0.02 & 0.05 & 0.01 * \\
\hline IOS $20 \mathrm{hz} 4 \mathrm{~h}$ & -0.01 & -0.02 & 0.01 & 0.48 & -0.01 & -0.04 & 0.03 & 0.09 \\
\hline \multicolumn{9}{|c|}{ IOS $20 \mathrm{hz}$ (difference $\mathrm{kPa} / \mathrm{l} / \mathrm{s}$ ) } \\
\hline IOS $20 \mathrm{hz} 4 \mathrm{~h}$ & -0.01 & -0.01 & 0.00 & 0.80 & -0.72 & -0.03 & -0.68 & 0.35 \\
\hline IOS $20 \mathrm{hz} 24 \mathrm{~h}$ & -0.01 & -0.01 & 0.00 & 0.73 & 0.00 & -0.03 & 0.02 & 0.04 * \\
\hline \multicolumn{9}{|c|}{ FeNO (difference ppb) } \\
\hline $3 \mathrm{~h}$ & -5 & -4 & -1 & 0.75 & -2 & -4 & 2 & 0.71 \\
\hline $5 \mathrm{~h}$ & -4 & -2 & -2 & 0.37 & -7 & -7 & -1 & 0.89 \\
\hline $24 \mathrm{~h}$ & -4 & -1 & -3 & 0.26 & 2 & -6 & 8 & 0.09 \\
\hline \multicolumn{9}{|c|}{ PWV (difference m/s) } \\
\hline $3 \mathrm{~h}$ & -0.1 & -0.2 & 0.2 & 0.47 & 0.1 & -0.6 & 0.8 & 0.03 * \\
\hline $6 \mathrm{~h}$ & 0.3 & 0.0 & 0.3 & 0.32 & 0.2 & -0.3 & 0.5 & 0.03 * \\
\hline $24 \mathrm{~h}$ & 0.6 & -0.4 & 1.0 & 0.04 * & 0.3 & -0.4 & 0.7 & 0.32 \\
\hline
\end{tabular}

0.02) one hour after the start of exposure on Oxford Street, compared to Hyde Park. Measurement of impulse oscillometry in volunteers with COPD demonstrated increased airway resistance at $5 \mathrm{~Hz}$ of $0.05 \mathrm{kPa} / 1 / \mathrm{s}(\mathrm{p}=0.01)$ four hours and at $20 \mathrm{~Hz}$ of $0.02(\mathrm{p}=0.04) 24 \mathrm{~h}$ after exposure began on Oxford Street. PWV increased by $0.8 \mathrm{~m} / \mathrm{s}$ and $0.5 \mathrm{~m} / \mathrm{s}$ three hours and six hours after exposure started on Oxford street respectively.

There were no changes in FeNO in either group between the two sites.

Preliminary multivariate analysis has so far found no associations with individual particulate measurements.

Conclusions These findings show that airways obstruction occurred in both the healthy volunteers and COPD patients exposed to ambient levels of diesel pollution on a busy London Street. The associated vascular dysfunction was more prominent in COPD patients. Further analyses of markers of inflammation in the collected samples are now needed to ascertain the mechanistic cause of the pathophysiological findings.

\section{S106 REVIEW OF EUROPEAN COPD AUDIT DATA: FACTORS AFFECTING LENGTH OF STAY}

${ }^{1} \mathrm{M}$ Ruparel, ${ }^{2} \mathrm{JL}$ López-Campos, ${ }^{3} \mathrm{~F}$ Pozo-Rodriguez, ${ }^{3} \mathrm{~A}$ Castro-Acosta, ${ }^{4} \mathrm{~S}$ Hartl, ${ }^{5} \mathrm{CM}$ Roberts. 'Royal Free Hospital, London, UK; ${ }^{2}$ Unidad Medico-Quirurgica de Enfermedades Respiratorias/Instituto de Biomedicina de Sevilla (IBiS), Hospital Universitario Virgen Del Rocio/CIBER de Enfermedades Respiratorias (CIBERES), Seville, Spain; ${ }^{3}$ Centre for Biomedical Research on Respiratory Diseases (CIBERES). Instituto de Salud Carlos III, Madrid, Spain; ${ }^{4}$ Ludwig Boltzmann Institute of COPD and Respiratory Epidemiology, Otto Wagner Hospital, Vienna, Austria; ${ }^{5}$ Barts and the London School of Medicine and Dentistry, Queen Mary, University of London, London, UK

10.1136/thoraxjnl-2014-206260.112 
Abstract S106 Table 1 Odds ratios for various factors resulting in LOS > median. Numbers on $y$ axis correspond to first column in below

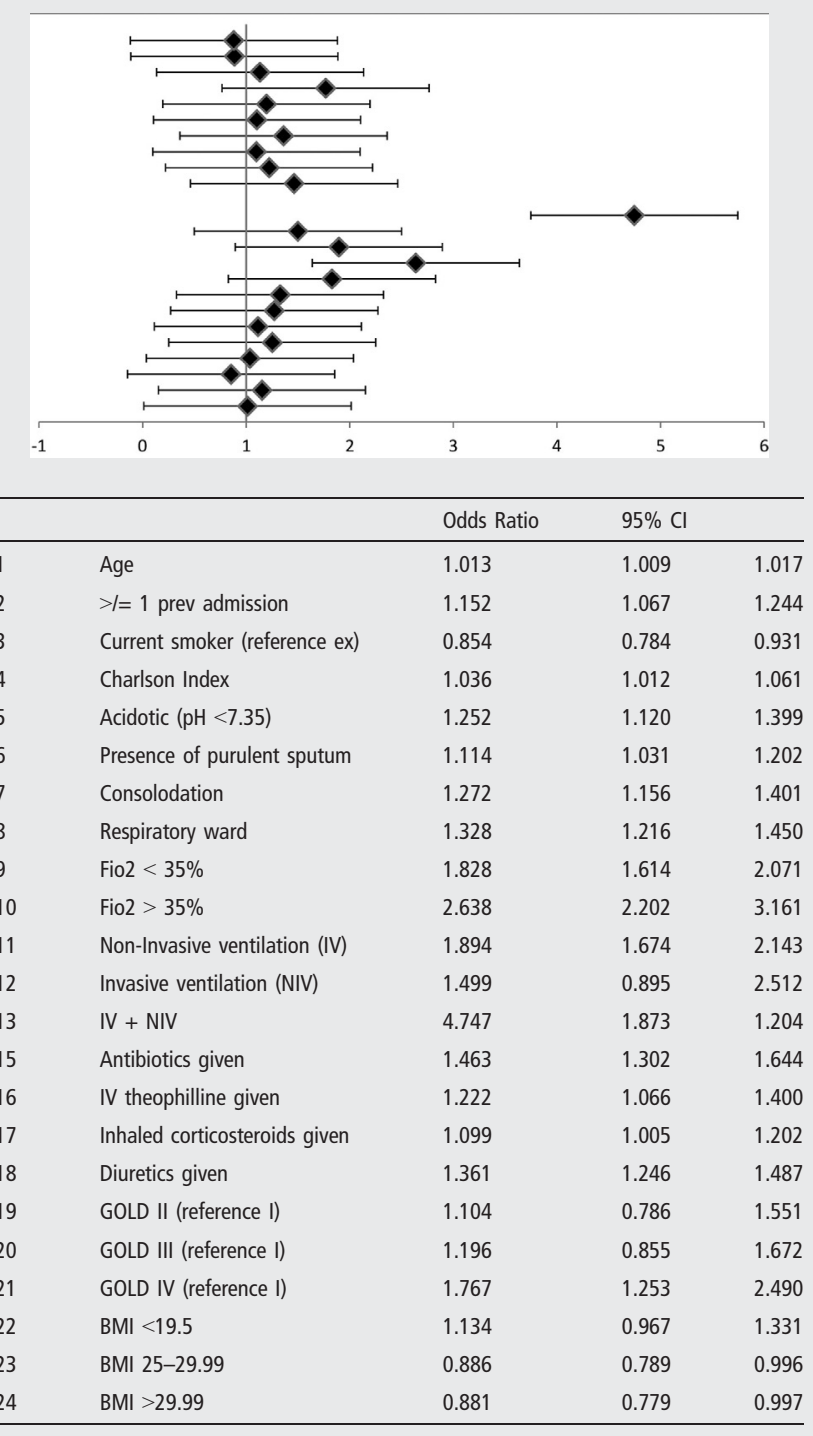

Introduction and objectives The major cost to health services of COPD care is hospital admission for exacerbation. Reducing length of stay (LOS) will reduce cost, yet there is wide variability across patients and hospitals. We test the hypothesis that these variations may be attributed to either patient characteristics, hospital characteristics and/or the so-called hospital-clustering effect, which indicates that patients with similar characteristics may experience different processes of care and outcomes depending on the hospital to which they are admitted.

Methods The European COPD Audit which was carried out in 432 hospitals from 13 countries, included data from 16,018 patients admitted over an 8 week period. The recorded variables included information on the patient and disease characteristics, resources available and clinical practice. Variables in each category associated with LOS were evaluated by a multivariate multilevel analysis and expressed as odds ratios (OR).

Results Mean LOS was 8.7 days (median: 7, standard deviation: 8.3, interquartile range: 4-11). Factors associated with an LOS higher than the median (see figure) were clinical with the highest impact in patients with use of mechanical ventilation (OR: 4.74) and higher oxygen flows (OR 2.63). In-hospital treatments, comorbidities and patient-related variables including GOLD class IV (OR 1.77) were also significant. These relationships were maintained with respect to longer LOS ( $>21$ days). Neither the day of admission, nor any of the resource variables were associated with significant differences in LOS. The crude variability of LOS between the different countries was reduced after accounting for these clinical factors and the clustering effect.

Conclusions This study demonstrates a noteworthy reduction in the observed crude inter-hospital variation in LOS after accounting for the hospital-cluster effect and patient related variables. This emphasises the predictor importance of the patients' clinical conditions and interventions, and understates the impacts of hospital resources and organisational factors. This "real-life" reflection may highlight some valid learning points that may help us to determine which achievable strategies are most relevant to improve outcomes.

\section{S107 EXPLAINING THE MORTALITY GAP IN COPD PATIENTS AFTER MYOCARDIAL INFARCTION: DATA FROM THE UK MYOCARDIAL ISCHAEMIA NATIONAL AUDIT PROJECT (MINAP)}

${ }^{1} \mathrm{KJ}$ Rothnie, ${ }^{1} \mathrm{~L}$ Smeeth, ${ }^{1} \mathrm{E}$ Herrett, ${ }^{1} \mathrm{~N}$ Pearce, ${ }^{2} \mathrm{H}$ Hemingway, ${ }^{3} \mathrm{~A}$ Timmis, ${ }^{4} \mathrm{~J}$ Wedzicha, ${ }^{1} \mathrm{JK}$ Quint. 'London School of Hygiene and Tropical Medicine, London, UK; ${ }^{2}$ University College London, London, UK; ${ }^{3}$ Barts and the London School of Medicine, London, UK; ${ }^{4}$ Imperial College London, London, UK

\subsection{6/thoraxjnl-2014-206260.113}

Introduction COPD patients are at increased risk of myocardial infarction (MI) and have increased mortality after an MI. Although some of this increased risk may be due to COPD itself, differences in management after an MI may play a role. ${ }^{1}$ We therefore investigated whether the increased in-hospital and 180 day mortality for COPD patients could be explained by differences in in-hospital and discharge treatment.

Methods Patients with a first MI between 2003-2013 were identified from the UK MINAP database. COPD patients had a record of obstructive airway disease, smoking history and were aged $>35$ years. Logistic regression was used to compare mortality in-hospital and at 180 days post-discharge between COPD and non-COPD patients. All models were adjusted for age, sex, smoking, previous cardiovascular disease, renal failure, diabetes and cardiovascular drugs used on admission. Variables relating to in-hospital management (delay in diagnosis, use of reperfusion and time to reperfusion/use of angiography in-hospital) and use

Abstract S107 Table 1 Differences in mortality after an MI between COPD and non-COPD patients. All odds ratios compare COPD to non-COPD patients

\begin{tabular}{llll}
\hline & $\begin{array}{l}\text { Minimally } \\
\text { adjusted OR } \\
(95 \% \mathrm{Cl})\end{array}$ & $\begin{array}{l}\text { Adjusted for in- } \\
\text { hospital factors } \\
\text { OR }(95 \% \mathrm{Cl})\end{array}$ & $\begin{array}{l}\text { Adjusted for use } \\
\text { of secondary } \\
\text { prevention } \\
\text { OR }(95 \% \mathrm{Cl})\end{array}$ \\
\hline $\begin{array}{l}\text { STEMIs } \\
\text { In-hospital mortality }\end{array}$ & $1.24(1.10-1.41)$ & $1.11(0.91-1.35)$ & - \\
$\begin{array}{l}180 \text { day mortality } \\
\text { Non-STEMls }\end{array}$ & $1.45(1.33-1.59)$ & $1.45(1.34-1.57)$ & $1.29(1.18-1.41)$ \\
$\begin{array}{l}\text { In-hospital mortality } \\
180 \text { day mortality }\end{array}$ & $1.34(1.24-1.45)$ & $1.16(1.07-1.26)$ & - \\
\hline
\end{tabular}

